\title{
Hemozoin From the Liver Fluke, Opisthorchis felineus, Modulates Dendritic Cell Responses in Bronchial Asthma Patients
}

\begin{abstract}
Irina V. Saltykova ${ }^{1,2,3 *}$, Wannaporn Ittiprasert ${ }^{3}$, Kseniya V. Nevskaya ${ }^{1}$, Yulia B. Dorofeeva ${ }^{1}$, Natalia A. Kirillova ${ }^{2}$, Evgeniy S. Kulikov ${ }^{1}$, Vladimir V. Ivanov ${ }^{1}$, Victoria H. Mann ${ }^{3}$, Alexandra G. Pershina ${ }^{1}$ and Paul J. Brindley ${ }^{3 *}$

${ }^{1}$ Central Research Laboratory, Siberian State Medical University, Tomsk, Russia, ${ }^{2}$ Department of General Practice and Polyclinic Therapy, Siberian State Medical University, Tomsk, Russia, ${ }^{3}$ Department of Microbiology, Immunology and Tropical Medicine, Research Center for Neglected Diseases of Poverty, School of Medicine \& Health Sciences, George Washington University, Washington, DC, United States
\end{abstract}

\section{OPEN ACCESS}

Edited by:

Yadong Zheng,

State Key Laboratory of Veterinary Etiological Biology, Lanzhou Institute of Veterinary Research (CAAS), China

Reviewed by:

Xianyong Liu,

China Agricultural University

(CAU), China

Si-Yang Huang,

Yangzhou University, China

*Correspondence:

Irina V. Saltykova

ira.saltikova@mail.ru

Paul J. Brindley

pbrindley@gwu.edu

Specialty section:

This article was submitted to

Parasitology,

a section of the journal

Frontiers in Veterinary Science

Received: 17 July 2019

Accepted: 16 September 2019

Published: 16 October 2019

Citation:

Saltykova IV, Ittiprasert $W$ Nevskaya KV, Dorofeeva YB, Kirillova NA, Kulikov ES, Ivanov W,

Mann VH, Pershina AG and Brindley PJ (2019) Hemozoin From the Liver Fluke, Opisthorchis felineus, Modulates Dendritic Cell Responses in Bronchial Asthma Patients.

Front. Vet. Sci. 6:332 doi: 10.3389/fvets.2019.00332
Aims: There is a general, inverse relationship between helminth infection and allergic diseases including bronchial asthma (BA). Proteins and other mediators released from parasitic worms exert cogent downmodulation of atopic and other allergic reactivity. We investigated the immune activities of an immortalized murine dendritic cell (mDC) line (JAWSII) and of primary human dendritic cells (hDCs) collected from study participants with and without BA after Opisthorchis felineus hemozoin $(\mathrm{OfHz})$ treatment.

Methods and Results: in vitro, expression of lymphocyte-activating factors - T helper 1 (Th1) induction and anti-inflammatory cytokines including tumor necrosis factor alpha

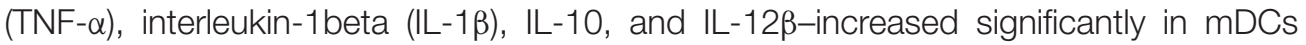
pulsed with $\mathrm{OfHz}$. In parallel, primary dendritic cells (hDC) from cases clinically diagnosed with BA along with healthy controls were exposed ex vivo to $\mathrm{OfHz}$ in combination with lipopolysaccharide (LPS). Whereas no significant change in the cellular maturation markers, CD83, CD86, and CD40, was apparent in BA vs. healthy hDC, pulsing hDC from BA with $\mathrm{OfHz}$ with LPS induced significant increases in expression of IL-10 and IL-12 $\beta$, although not of TNF- $\alpha$ or tumor growth factor-beta (TGF- $\beta$ ).

Conclusions: Liver fluke hemozoin $\mathrm{OfHz}$ stimulated production of Th1 inducer and anti-inflammatory cytokines $\mathrm{IL}-10$ and $\mathrm{IL}-12 \beta$ from BA-hDC pulsed with $\mathrm{OfHz}$, an outcome that enhances our understanding of the mechanisms whereby opisthorchiasis contributes to protection against the atopic disease in liver fluke infection-endemic regions.

Keywords: Th1, immunoregulation, cytokine, asthma, dendritic cell, hemozoin, Opisthorchis

\section{INTRODUCTION}

Helminth parasites establish chronic infections, characterized by modulation of both the innate and adaptive host immune response. A generalized, negative relationship between helminth infection and immune-related disorders is apparent for several disorders and helminth parasite species (1-3). Excretory-secretory (ES) products released from eukaryotic parasites are potent 
modulators of the immune response,which is central to the survival of these pathogens and for the maintenance of a chronic infection. There is active, sustained investigation of the mechanisms of the immunomodulation induced by helminths and the characterization of parasite-derived products with immunomodulation properties for treatment and prevention of the autoimmune-related diseases $(4,5)$. Indeed, investigation of the activities and properties of ES products has provided insights into the mechanisms of the host immune response modulation by parasites, which may be exploited for therapeutic intervention for allergic, autoimmune, metabolic, and inflammatory diseases (6-9).

Hemozoin $(\mathrm{Hz})$ is an ES product with immunomodulatory properties known in a variety of eukaryotic parasites including Plasmodium falciparum (10), schistosomes (11-14), and liver flukes $(15,16) . \mathrm{Hz}$ is an inert, dark brown crystalline polymer of ferriprotoporphyrin IX produced by blood-feeding parasites. The synthesis of $\mathrm{Hz}$ by the parasite results in the detoxification of heme from digested blood. The effects of $\mathrm{Hz}$ purified from parasites [native $\mathrm{Hz}(\mathrm{nHz})]$ and of $\mathrm{Hz}$ synthesized $(\mathrm{sHz})$ from hemin-synthetic $\mathrm{Hz}$ ( $\beta$-hematin) have been investigated in vitro and in vivo. In vitro, dendritic cell (DC) and other cells such as monocytes phagocytize $\mathrm{nHz}$ (17). ES products of many helminths suppress DC maturation and modulate DC response to lipopolysaccharide (LPS) and other stimuli. Similar responses have been described following the incubation of $\mathrm{DC}$ with $\mathrm{nHz}$ purified from $P$. falciparum $(P f \mathrm{~Hz})$. Exposure to $P f \mathrm{~Hz}$ impairs the maturation of immature DC (18). $P f \mathrm{~Hz}$ inhibits the loss of podosomes by DC and inhibits the upregulation of CD83 after stimulation by LPS, a potent activator of DC maturation (19). The addition of $\mathrm{PfHz}$ or $\mathrm{sHz}$ decreases production of LPS/IFN-promoted interleukin (IL)-12p70 [T helper 1 (Th1) responses development] and increases immune homeostasis cytokines including IL-10 and tumor necrosis factor alpha (TNF$\alpha$ ) from peripheral blood mononuclear cells (PBMCs) and $\mathrm{CD}_{14}{ }^{+}$antigen-presenting cells (20).

Because the exposition and subsequent increased acceptance of the hygiene hypothesis, many diseases have been linked to exposure during childhood to microbial and eukaryotic pathogens, including helminth parasites (21-23). Asthma is a chronic inflammatory disease of the lung airways especially of the bronchi and bronchioles. Numerous factors contribute to asthma including environmental insults and allergens such as dust mites, pollen, and airborne pollutants from motor vehicles, along with a susceptible genetic phenotype. A rapid increase of incidence of asthma is evident in developed countries but is generally unapparent in less developed countries, especially in regions endemic for parasites. According to the hygiene hypothesis, the appearance of allergic diseases is inversely related to the decrease in prevalence of parasite infection, which can modulate the immune response and establish a host-parasite relationship and immunological milieu that accommodates both the helminth and its host (24-27). This provides a new area in which to search for intervention for the treatment and prevention of asthma.

Infection with the food-borne trematode Opisthorchis felineus is a highly prevalent liver fluke infection in Western Siberia, Russia (28, 29). Inverse relationships between O. felineus infection and allergy in a liver fluke endemic region have been reported (30). Epidemiological investigation has indicated that opisthorchiasis has a negative association with skin prick test reactivity (31). Infection with $O$. felineus diminishes the risk of atopic bronchial asthma (BA) associated with the SOCS5 gene polymorphism (32). The treatment with filarial cystatin of human PBMCs from patients who are sensitive to timothy grass pollen caused a Th1 polarization, pointing to a potential therapy for asthmatics (33). Infection with Schistosoma japonicum and Heligmosomoides polygyrus can downregulate allergic airway inflammation $(34,35)$. However, given that intact infectious agents are likely to be pathogenic, parasite extracts such as O. felineus $\mathrm{Hz}(\mathrm{O} f \mathrm{~Hz})$ might offer a safer biotherapeutic. Accordingly, here, we addressed here whether $\mathrm{OfHz}$ modulates DC immune function in patients during BA, a Th2 immune response-associated disease.

\section{MATERIALS AND METHODS \\ $\mathrm{Hz}$ Extraction and Purification}

To extract $\mathrm{Hz}$ from Opisthorchis felineus, we used a slightly modified protocol based on methods reports for studies on host immunomodulation to $\mathrm{Hz}$ from Schistosoma mansoni (14) and Plasmodium falciparum (18). The purification of $\mathrm{OfHz}$ involved the removal of host or parasite products adsorbed on the surface of $\mathrm{OfHz}$, which leads to variable and undetermined residue by decontamination of lipids and proteins. Briefly, O. felineus mature worms were collected from $O$. felineus metacercariaeinfected hamster (50 metacercariae/hamster, Supplement 1). Pooled mature worms were washed three times with $1 \times$ phosphate-buffered saline (PBS), and then $7 \mathrm{~mL}$ of packed parasites was final resuspended in PBS with $10 \mathrm{~mL}$ total volume. Worms were sonicated on ice until homogenized; the lysate was subjected to centrifugation at $1,000 \times \mathrm{g}$ for $60 \mathrm{~s}$ at room temperature. The upper aqueous contents of the supernatant were transferred to a new tube, and the pellet containing the $\mathrm{Hz}$ was collected after centrifugation at $8,000 \times \mathrm{g}$ for $20 \mathrm{~min}$. Pelleted $\mathrm{Hz}$ was resuspended in PBS and then subjected to precipitation in chloroform, methanol, and water (36). Pelleted $\mathrm{Hz}$ was resuspended in $2 \mathrm{~mL}$ of PBS, briefly sonicated on ice, and exposed to $1 \%$ proteinase $\mathrm{K}$ at $37^{\circ} \mathrm{C}$ for $18 \mathrm{~h}$. Subsequently, the $\mathrm{Hz}$ was re-pelleted at $10,000 \times \mathrm{g}$ for $20 \mathrm{~min}$ and washed sequentially three times in PBS containing $2 \%$ sodium dodecyl sulfate (SDS), three times in $0.1 \mathrm{M}$ of $\mathrm{NaHCO}_{3}$ (pH 9.1) containing $2.5 \%$ SDS, and five times in distilled water. The contamination of $\mathrm{Hz}$ samples was assessed for proteins by silverstained SDS-polyacrylamide gel electrophoresis (PAGE) and for nucleic acids by use of ethidium bromide-stained agarose gels. The absence of $O$. felineus egg contamination was confirmed by light microscopy.

Levels of endotoxin level were determined using an endpoint chromogenic Limulus amebocyte lysate assay (Lonza AG, Visp, Switzerland,). A standard curve was established using a range of concentrations of hematin diluted in $100 \mathrm{mM}$ of $\mathrm{NaOH}, 2 \%$ SDS, and $3 \mathrm{mM}$ of EDTA, for which absorbance at $401 \mathrm{~nm}$ was measured using a spectrophotometer. To determine the concentration of $\mathrm{OfHz}$, the absorbance at $401 \mathrm{~nm}$ of aliquots 
of $\mathrm{OfHz}$ dissolved in $100 \mathrm{mM}$ of $\mathrm{NaOH}, 2 \% \mathrm{SDS}$, and $3 \mathrm{mM}$ of EDTA was compared with the standard curve.

\section{Stimulation-Exposure of JAWSII Cells to $\mathrm{OfHz}$}

The semi-adherent JAWSII cell line, a granulocyte-macrophage colony-stimulating factor (GM-CSF)-dependent dendritic (DC) line established from bone marrow cells of p53-knockout $\mathrm{C} 57 \mathrm{Bl} / 6$ mouse, was purchased from the American Type Culture Collection (CRL-1194; ATCC, Manassas, VA). JAWSII cells were maintained in complete Roswell Park Memorial Institute medium (RPMI) 1640 culture with $4 \mathrm{mM}$ of L-glutamine, HEPES (Thermo Fisher Scientific) consisting of 10\% (v/v) fetal bovine serum (FBS), $5 \mathrm{ng} / \mathrm{mL}$ of GM-CSF, $10 \mathrm{U} / \mathrm{mL}$ of penicillin and $100 \mu \mathrm{g} / \mathrm{mL}$ of streptomycin, $0.5 \mathrm{mM}$ of $2-\mathrm{ME}$, and $1 \mathrm{mM}$ of sodium pyruvate, in $5 \% \mathrm{CO}_{2}$ in air at $37^{\circ} \mathrm{C}$. Cultures were maintained by transferring nonadherent cells to a centrifuge tube and treating attached cells with $0.25 \%$ trypsin- $-0.03 \%$ EDTA (Gibco) at $37^{\circ} \mathrm{C}$ for $5 \mathrm{~min}$, followed by pooling the two populations of cells together and dispensing into new flasks and/or for downstream analysis. To stimulate JAWSII cells, 300,000 cells $/ \mathrm{mL}$ were seeded into wells of 6-well plates for $24 \mathrm{~h}$ before exposure to liver fluke $\mathrm{Hz}, \mathrm{OfHz}$. The cells were divided into three groups: control (no treatment), mock $(1 \times$ PBS treatment), and $O f \mathrm{~Hz}$-treated (100 nm of $O f \mathrm{~Hz}$ in $1 \times \mathrm{PBS})$. JAWSII cells were pulsed with $O f \mathrm{~Hz}$ for $48 \mathrm{~h}$ and harvested as above. The cells were washed three times with $1 \times$ PBS before proceeding to RNA extraction.

\section{RNA Extraction and Quantitative Reverse Transcriptase Polymerase Chain Reaction (RT-PCR) of Anti-inflammatory and Inflammatory Cytokine}

Total RNA was extracted from JAWSII and $O f H z$-treated JAWSII cells using the RNAzol RT reagent (Molecular Research Center, Inc., Cincinnati, OH), which removes contaminated DNA (37), and its concentration and purity were determined using the NanoDrop ND-1000 spectrophotometer (OD260/280, 2.0). RNAs were reverse transcribed into cDNA using iScript Reverse Transcript (Bio-Rad). First-strand cDNA was performed RTqPCR using SsoAdvanced Universal SYBR Green Supermix (Bio-Rad) and run in triplicate using the iQ5 Real time PCR thermal cycler (Bio-Rad); thermal cycling was as follows: initial denaturation at $95^{\circ} \mathrm{C}$ for $30 \mathrm{~s}, 40$ amplification cycles each consisting of denaturation at $95^{\circ} \mathrm{C}$ for $15 \mathrm{~s}$, annealing at $60^{\circ} \mathrm{C}$ for $30 \mathrm{~s}$, and final heating at $60-95^{\circ} \mathrm{C}$ to obtain the melting curve. Samples were run in triplicates after which the output was analyzed using the iQ5 software (Bio-Rad). The delta-delta Ct method with normalization to mouse GAPDH expression (38) was used to calculate the relative expression of the IL-1 $\beta$, IL-10, IL-12b, and TNF- $\alpha$ genes. The data were expressed as differential fold change compared with the control group, with fold changes reported as mean and $95 \%$ confidence interval (CI) of difference. The statistical significance of cytokine transcript induction from Of Hz-treated groups were compared with control groups using two-way analysis of variance (ANOVA), followed by Dunnett's multiple comparison test (Prism software).

\section{Monocyte-Derived DCs}

Purification of human PBMCs was performed using a twostep gradient centrifugation (39). Briefly, peripheral blood was diluted with Hank's balanced salt solution (HBSS) (1:1), loaded on a Ficoll-Hypaque gradient (Sigma, Moscow, Russia), and centrifuged for $30 \mathrm{~min}$ at $600 \times \mathrm{g}$ at room temperature. PBMCs were collected, washed twice in HBSS ( $\mathrm{pH}$ 7.4), resuspended in serum-free RPMI, and mixed with $1.5 \times$ volume of isotonic Percoll solution (IPS) (Percoll:PBS, 9:1 v/v, $p=1.123 \mathrm{~g} / \mathrm{mL}$ ). Thereafter, PBMCs were overlaid carefully with Percoll-RPMI solution 1 (IPS:RPMI, $p=1.064 \mathrm{~g} / \mathrm{mL}$ ) and Percoll-RPMI solution 2 (IPS:RPMI, $p=1.032 \mathrm{~g} / \mathrm{mL}$ ). Monocytes were collected from the RPMI-Percoll interface after centrifugation at $2,000 \times \mathrm{g}$ for $50 \mathrm{~min}$ at $20^{\circ} \mathrm{C}$. The purity of monocytes was 79$87 \%$ as determined by flow cytometric quantification of $\mathrm{CD} 14^{+}$. positive cells. Monocytes were seeded into 24-well plates at $0.5-1$ $\times 10^{6}$ cells/well and cultured for $96 \mathrm{~h}$ in complete RPMI 1640 medium supplemented with $10 \%$ heat-inactivated FBS (HyClone, Thermo Fisher Scientific,), $50 \mu \mathrm{M}$ of $\beta$-mercaptoethanol, 110 $\mathrm{mg} / \mathrm{L}$ of $2 \mathrm{mM}$ of L-glutamine, $1 \times$ penicillin-streptomycin (PanEco, Russia) in the presence of GM-CSF $(100 \mathrm{ng} / \mathrm{mL})$, and IL-4 $(50 \mathrm{ng} / \mathrm{mL})$ (Sigma) in $5 \% \mathrm{CO}_{2}$ in air at $37^{\circ} \mathrm{C}$. Maturation of DC was induced by pulsing with LPS; immature DCs were incubated with LPS $(100 \mathrm{ng} / \mathrm{mL})$ and LPS plus $O f \mathrm{~Hz}(15 \mu \mathrm{g} / \mathrm{mL})$. DCs were harvested $36 \mathrm{~h}$ later and supernatants collected for immunoassays; aliquots of supernatants were stored at $-80^{\circ} \mathrm{C}$ for cytokine analysis.

\section{Immunoassays for DC Markers and Secreted Cytokines}

The levels of the co-stimulatory and maturation markers CD40, CD83, and CD86 on human DCs (40) were analyzed by flow cytometry using antibodies from BD Biosciences, San Diego, CA. Cells $\left(10^{4}\right)$ were monitored using the Accuri C6 flow cytometer (Becton Dickinson, Franklin Lakes, NJ), and the data analyzed using the Cell Quest software (BD Biosciences). Levels of IL-10, IL-12 $\beta$, TNF- $\alpha$, and tumor growth factor-beta (TGF- $\beta$ ) were measured by enzyme-linked immunosorbent assay (ELISA) (eBioscience, Thermo Fischer Scientific).

\section{Study Participants Diagnosed With BA}

The Ethics Committee of the Siberian State Medical University, Russia, approved the study, with approval number 4815. All participants provided written consent. Blood from 10 cases with severe BA and nine healthy volunteers (personnel at the Siberian State Medical University, Russia) was examined in this study. The elderly asthma patients ( $>58$ years old), eight females and one male, were diagnosed as BA (Table 1) according to the Global Initiative for Asthma criteria (41), using a standardized questionnaire and results of physical and laboratory examinations for more than 20 years. Non-atopic and nonsmoking individuals without a family history of asthma/allergy were included as healthy controls. All of the BA cases and the healthy controls were negative for O. felineus infection, 
TABLE 1 | Characteristics of study participants.

\begin{tabular}{lcc}
\hline & $\begin{array}{c}\text { Bronchial } \\
\text { asthma }(\boldsymbol{n}=\mathbf{1 0})\end{array}$ & $\begin{array}{c}\text { Control } \\
(\boldsymbol{n}=\mathbf{8})\end{array}$ \\
\hline Age in years & $64.5 \pm 5.7$ & $20.6 \pm 1.4$ \\
Females/males & $9 / 1$ & $7 / 2$ \\
Duration of asthma (years) & $20.7 \pm 9.1$ & $\mathrm{NA}$ \\
FEV1 $(\%)$ & $64.2 \pm 7.8$ & $\mathrm{NA}$ \\
Emergency medical care in the & $2.6 \pm 1.2$ & None \\
past year & & None \\
PC20 (mg/mL) & $0.06 \pm 0.0$ & \\
\hline
\end{tabular}

Data presented as mean \pm SD. FEV1, forced expiratory volume per second (FEVI); PC20, histamine provocative concentration causing a $20 \%$ fall in FEV1.

by stool examination, at the time of blood collection. Table 1 outlines the epidemiological characteristics and other records of the participants.

\section{RNA Extraction From Human DCs and Differential Cytokine Gene Expression}

Total RNAs were isolated from non-stimulated human DCs and from DCs stimulated with $\mathrm{Hz}$ using the TRIzol (Invitrogen, USA) extraction method followed by purification on columns (Qiagen, UK). Total RNA was reverse transcribed into cDNA following the protocol for RevertAid First-Strand cDNA Synthesis Kit (Thermo Fisher). The cDNAs were amplified using PCR with gene-specific primers designed by using CLC Main Workbench 7.0 (CLC Bio, Aarhus, Austria). Each PCR was carried out in duplicate with optimized primer concentrations using qPCRmixHS SYBR (Evrogen, Russia) in a thermal cycler CFX-96 (Bio$\mathrm{Rad})$, with the following thermal cycling conditions: one cycle of $10 \mathrm{~min}$ denaturation at $95^{\circ} \mathrm{C} ; 34-37$ cycles of $1 \mathrm{~min}$ at $94^{\circ} \mathrm{C}$, $1 \mathrm{~min}$ at $53-57^{\circ} \mathrm{C}$, and $1 \mathrm{~min}$ at $72^{\circ} \mathrm{C}$; and a final extension step at $72^{\circ} \mathrm{C}$ for $10 \mathrm{~min}$. A dissociation curve was included in each run to ensure specificity of amplification. Beta-actin (ACTB) was used as the reference gene. The relative expression of genes was calculated using delta-delta Ct method; data were expressed as fold change compared with the untreated group (38).

\section{Statistics}

Data analysis was accomplished with the assistance of the Prism 6, GraphPad software. Cell culture data were analyzed by twoway ANOVA with Dunnett's multiple comparison test. When the variables did not show normal distribution, they were compared using the Mann-Whitney $U$-test (two-tailed). The Wilcoxon matched pairs test was applied to dependent samples $(P \leq 0.05$ were considered to be statistically significant.

\section{RESULTS}

\section{Chemokine Transcript Profiles in JAWSII After OfHz Stimulation}

The transcript levels encoding IL- $1 \beta$, IL-10, IL- $12 \beta$, and TNF$\alpha$ were analyzed after JAWSII cells were pulsed with $100 \mathrm{~nm}$ of

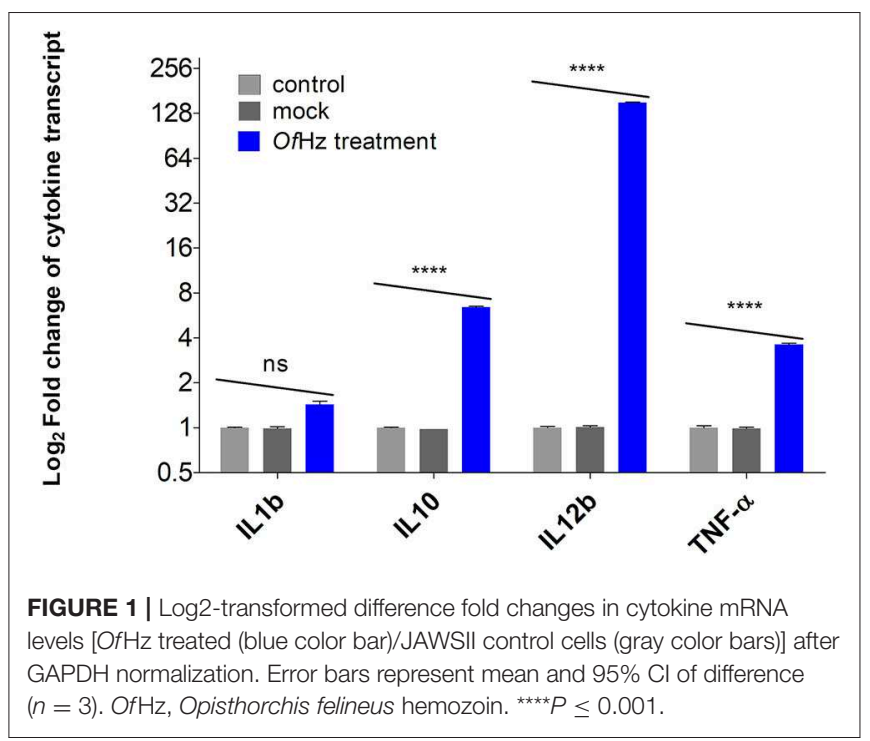

Of Hz in PBS for $48 \mathrm{~h}$. Whereas, differences in expression of IL$1 \beta$ in $O f H z$-treated and control groups (mock and no treatment) were not seen, there were statistically significant increases in transcription of IL-10, IL-12 $\beta$, and TNF- $\alpha$ by 6.4-, 151-, and 3.6-fold, respectively (Figure 1).

\section{Maturation of DCs Induced by LPS Was Unaffected by $\mathrm{OfHz}$}

The effect of $\mathrm{OfHz}$ on maturation of DCs in response to LPS was investigated by analysis of hallmark markers of the mature DC phenotype (40). Monocyte-derived DCs from participants with BA and controls were stimulated with LPS alone and in combination with $\mathrm{OfHz}$. CD83, CD40, and CD86 expression on DCs were measured. Expression of CD83, CD40, and CD86 was unaffected by $O f \mathrm{~Hz}$ in DCs activated by LPS (Figure 2, Table S1).

\section{Change of DCs Cytokines Expression and Secretion Related to OfHz Treatment}

$\mathrm{DCs}$ from BA cases exposed in vitro to $\mathrm{O} \mathrm{Hz}$ exhibited significant upregulation of expression of IL10 and IL12b. In addition, we measured the levels of IL-10, TGF- $\beta$, TNF- $\alpha$, and IL-12 $\beta$ by ELISA in culture supernatants. Concentrations of IL-10 and IL$12 \beta$ were increased in supernatants of the DC from the BA cases treated with $\mathrm{OfHz}$ in comparison with non-OfHz-treated DCs from BA cases. Thus, the IL-10 and IL-12b gene expression and ELISA data were in concordance. By contrast, treatment of DC donated by healthy controls with $\mathrm{OfHz}$ failed to affect cytokine gene expression and secretion (Figure 3).

\section{DISCUSSION}

Synthetic $\mathrm{Hz}$ has been investigated as an adjuvant in the antiallergen vaccines. Atopic dermatitis that develops in beagles is similar to that seen in humans and is associated with elevated titers of IgE antibodies against the house dust mite allergen, Derf2. Immunization of dogs with Derf2 together with alum 


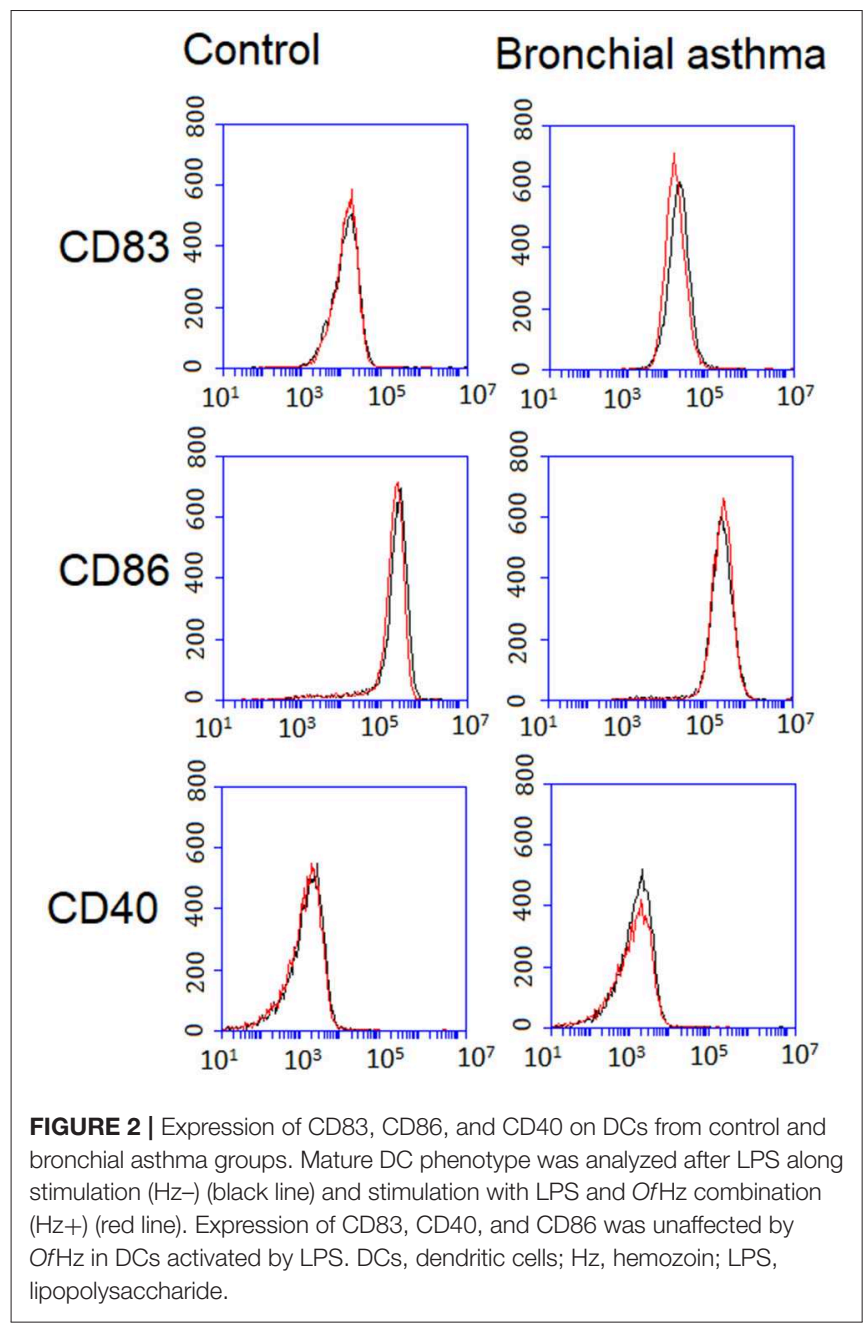

and/or sHZ, with subsequent sensitization by the allergen, provoked significantly elevated levels of IgG2, but not IgG1, antibodies in the sHz-treated group that resembled a Th1-like immune response (42). Treatment of PBMCs from healthy, malaria-free donors with $\mathrm{sHz}$ induced increases in IL-12p40 and IL-10 transcripts at $24 \mathrm{~h}$ of exposure with further stabilization of the expression levels of the cytokines relative to control conditions (43). Much less in known about properties of $\mathrm{Hz}$ isolated from blood-feeding helminths.

This is the first report to investigate the effect of liver fluke $\mathrm{Hz}$ on immature mouse DC cytokine expression level and immunomodulation activity on human DC maturation and cytokine expression and secretion. Specifically, the study investigated cytokine responses in an immature DC, JAWSII cells, following $O f \mathrm{~Hz}$ stimulation to estimate $\mathrm{OfHz}$ immunomodulation activity. Second, using leads from the responses of these JAWSII monocytes, we investigated the ability of stimulation with $\mathrm{OfHz}$ to affect LPS-induced maturation of human DCs and the consequent cytokine responses. Two groups of participants were included in the study to isolate monocytes for DCs generation: healthy volunteers and BA adults. Initially,

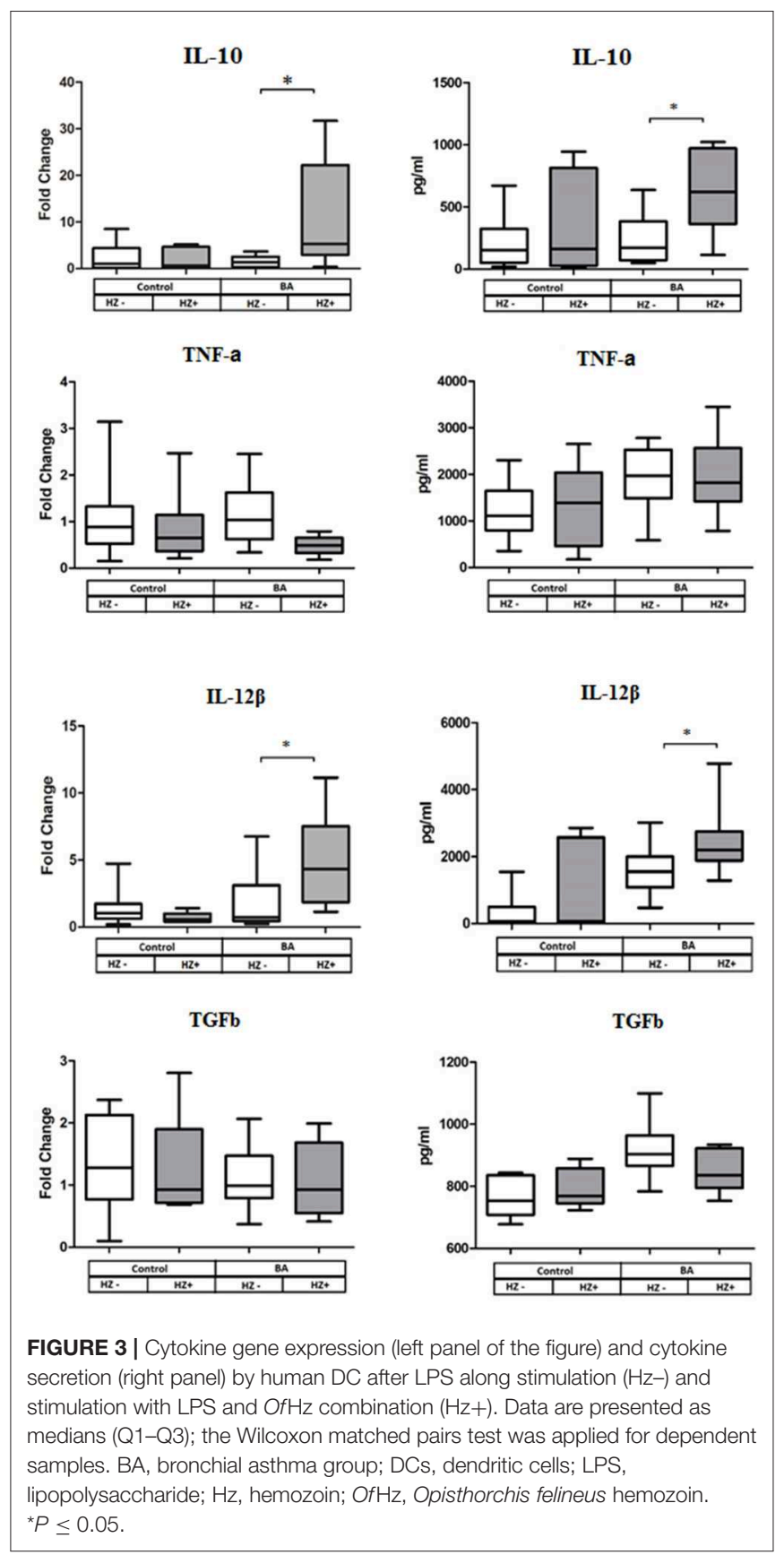

exposure to $\mathrm{OfHz}$ induced expression of IL-12 $\beta$, IL-10, and TNF- $\alpha$ in JAWSII. Immune-activating and immune-suppressive effects have been reported for $\mathrm{Hz}$ in experiments in vitro.

DCs play critical roles in determining T-cell differentiation in the context of allergen exposure (23). Marked differences were evident between asthma and healthy control groups in the expression and release of cytokines by DCs in response to co-incubation with $\mathrm{OfHz}$ and LPS. Of Hz potentiated the upregulation by LPS of cytokines IL-10 and IL-12 $\beta$ by human DC but only in the asthma group. There was no clear trend in IL-12 $\beta$ production by DCs in the asthma-free group in 
response to $O f \mathrm{~Hz}$. In general, we observed the variable individual responses in cytokine production by DCs after $\mathrm{O} f \mathrm{~Hz}$ exposure among the healthy control participants. Cell immunophenotypic characteristics can influence diverse responses to stimulation by Hz. Fibronectin incubated at physiologic concentrations with fibronectin-free $\mathrm{Hz}$ binds with high affinity to $\mathrm{Hz}$. The addition of fibronectin-containing $\mathrm{Hz}$ to adherent monocytes induces rapid stimulation of reactive oxygen species production and increase of TNF and monocyte chemotactic protein 1 by human monocytes. These responses arise from the interaction of fibronectin with fibronectin-receptors TLR4 and integrin CD11b/CD18 (44). TLR4 plays a key role in the allergic inflammation and severity of asthma (45).We hypothesize that the prevalence of the fibronectin receptors, notably TLR4, on the DC surface impairs the effects of stimulation by $\mathrm{OfHz}$.

Mature DCs secrete IL-10, IL-12, and proinflammatory cytokines, and these cytokines are known to participate in T-cell differentiation. Of $\mathrm{Hz}$ stimulation induced IL-12b, IL10 expression by immature DC and potentiated LPS-induced expression and production of IL-10 and IL-12 $\beta$ by human DCs in the BA asthma group. Asthma is a Th2-associated inflammatory disease with increased levels of $\operatorname{IgE}$ and Th2 cytokines. IL-12 as Th1-promoting cytokine has potential roles in the antagonism of Th2 cytokine responses and IgE synthesis that prevents the progress of airway inflammation in asthma (46). IL-10 has immunosuppressive properties, and induction of IL-10 by helminths is considered as one of the possible mechanisms of parasite survival in the anti-inflammatory environment (47). The production of Th1-promoting cytokine IL-12 $\beta$ and anti-inflammatory cytokine IL-10 by asthma DCs upon $\mathrm{OfHz}$ stimulation can suggest a role for $\mathrm{Hz}$ released during infection with Opisthorchis felineus in the Th1/Th2 balance regulation.

To extend the findings related to $\mathrm{OfHz}$-activated cytokine expression in $\mathrm{DC}$ and to determine whether $\mathrm{OfHz}$ may be immunomodulatory, maturation markers, cytokine expression, and secretion by human DCs were investigated. Of Hz did not appear to affect LPS-induced upregulation of key markers associated with a DC mature phenotype, including CD83, CD86, and CD40. It is noteworthy that exposure with crude O. felineus extract leads to the downregulation of costimulatory molecules CD83 and CD86 in LPS-induced DCs, generated from monocytes of asthma patients (48). Accordingly, Of Hz may be considered as a mediator that plays a key role in the $O$. felineus-derived immune response. Further investigation of the local liver immune cell response to secretion and accumulation of $\mathrm{OfHz}$ in bile ducts might provide insights into the chronic inflammation and other hepatic morbidity due to opisthorchiasis. Moreover, investigation of $\mathrm{OfHz}$ in asthma model in vivo can be expected to increase our understanding of the potential benefits of treatment with $O f \mathrm{~Hz}$ for the treatment of asthma.

In conclusion, our data demonstrate that $\mathrm{OfHz}$ induces expression of Th1 cytokines in immature mouse DC and that $\mathrm{OfHz}$ potentiates LPS-induced expression and production of IL-10 and IL-12 $\beta$ by DC in asthma patients. These results complement earlier findings that demonstrated the regulation of the host immune response by the helminth ES products, which play a protective role against allergy and allergic diseases (49), including findings in regions endemic for $O$. felineus, and that demonstrated the inverse relationship between opisthorchiasis and allergic diseases (31).

\section{DATA AVAILABILITY STATEMENT}

The datasets generated for this study are available on request to the corresponding author.

\section{ETHICS STATEMENT}

The studies involving human participants were reviewed and approved by The Ethics Committee of the Siberian State Medical University, Russia. The patients/participants provided their written informed consent to participate in this study. The animal study was reviewed and approved by The Ethics Committee of the Siberian State Medical University, Russia.

\section{AUTHOR CONTRIBUTIONS}

IS conceived and planned the experiments, analyzed the data, contributed to the interpretation of the results, and wrote the manuscript with input from all authors. WI performed the experiments, analyzed the data, and wrote the manuscript with input from all authors. YD, KN, WI, and VI performed the experiments. VI were involved in planning and supervised the work. EK and NK contributed to patients sample collection. AP and VM provided critical feedback and helped shape the research. PB supervised the project and wrote the manuscript.

\section{ACKNOWLEDGMENTS}

IS thanks the Fulbright Visiting Scholar program for support and acknowledges support of grant number 18-75-00036 from Russian Science Foundation (IS). We gratefully acknowledge the support of colleagues and collaborations in the Tomsk OPIsthorchiasis Consortium, TOPIC, www.topic-global.org. We also acknowledge support of award R01CA164719 (WI, VM and $\mathrm{PB}$ ) from the National Cancer Institute (NCI) and P50AI098639 (PB) from the National Institute of Allergy and Infectious Diseases (NIAID), National Institutes of Health (NIH). The contents are solely the responsibility of the authors and do not necessarily represent the official views of these sponsors.

\section{SUPPLEMENTARY MATERIAL}

The Supplementary Material for this article can be found online at: https://www.frontiersin.org/articles/10.3389/fvets. 2019.00332/full\#supplementary-material 


\section{REFERENCES}

1. Maizels RM, Yazdanbakhsh M. Immune regulation by helminth parasites: cellular and molecular mechanisms. Nat Rev Immunol. (2003) 3:733-44. doi: $10.1038 /$ nri1183

2. Maizels RM, McSorley HJ. Regulation of the host immune system by helminth parasites. J Allergy Clin Immunol. (2016) 138:666-75. doi: 10.1016/j.jaci.2016.07.007

3. Heylen M, Ruyssers NE, Gielis EM, Vanhomwegen E, Pelckmans PA, Moreels TG, et al. Of worms, mice and man: an overview of experimental and clinical helminth-based therapy for inflammatory bowel disease. Pharmacol Ther. (2014) 143:153-67. doi: 10.1016/j.pharmthera.2014.02.011

4. Broadhurst MJ, Leung JM, Kashyap V, McCune JM, Mahadevan U, McKerrow $\mathrm{JH}$, et al. IL-22+ CD4+ T cells are associated with therapeutic trichuris trichiura infection in an ulcerative colitis patient. Sci Transl Med. (2010) 2:60ra88. doi: 10.1126/scitranslmed.3001500

5. Pineda MA, Al-Riyami L, Harnett W, Harnett MM. Lessons from helminth infections: ES-62 highlights new interventional approaches in rheumatoid arthritis. Clin Exp Immunol. (2014) 177:13-23. doi: 10.1111/cei.12252

6. Shepherd C, Navarro S, Wangchuk P, Wilson D, Daly NL, Loukas A. Identifying the immunomodulatory components of helminths. Parasite Immunol. (2015) 37:293-303. doi: 10.1111/pim.12192

7. Alvarado R, O’Brien B, Tanaka A, Dalton JP, Donnelly S. A parasitic helminth-derived peptide that targets the macrophage lysosome is a novel therapeutic option for autoimmune disease. Immunobiology. (2015) 220:2629. doi: 10.1016/j.imbio.2014.11.008

8. Doonan J, Lumb FE, Pineda MA, Tarafdar A, Crowe J, Khan AM, et al. Protection against arthritis by the parasitic worm product ES-62, and its drug-like small molecule analogues, is associated with inhibition of osteoclastogenesis. Front Immunol. (2018) 9:1016. doi: 10.3389/fimmu.2018.01016

9. Dastpeyman M, Bansal PS, Wilson D, Sotillo J, Brindley PJ, Loukas A, et al. Structural variants of a liver fluke derived granulin peptide potently stimulate wound healing. J Med Chem. (2018) 61:8746-53. doi: 10.1021/acs.jmedchem.8b00898

10. Goldie P, Roth EF, Oppenheim J, Vanderberg JP. Biochemical characterization of Plasmodium falciparum hemozoin. Am J Trop Med Hyg. (1990) 43:584-96. doi: 10.4269/ajtmh.1990.43.584

11. Oliveira MF, Kycia SW, Gomez A, Kosar AJ, Bohle DS, Hempelmann E, et al. Structural and morphological characterization of hemozoin produced by Schistosoma mansoni and Rhodnius prolixus. FEBS Lett. (2005) 579:6010-6. doi: 10.1016/j.febslet.2005.09.035

12. Jiang Y, Xue X, Chen X, Zhuang W, Sun J, Shen L, et al. Hemozoin from Schistosoma japonicum does not affect murine myeloid dendritic cell function. Parasitol Res. (2010) 106:653-9. doi: 10.1007/s00436-009-1717-1

13. Xiao SH, Sun J. Schistosoma hemozoin and its possible roles. Int J Parasitol. (2017) 47:171-83. doi: 10.1016/j.ijpara.2016.10.005

14. Truscott M, Evans DA, Gunn M, Hoffmann KF. Schistosoma mansoni hemozoin modulates alternative activation of macrophages via specific suppression of Retnla expression and secretion. Infect Immun. (2013) 81:13342. doi: 10.1128/IAI.00701-12

15. Pershina AG, Saltykova IV, Ivanov VV, Perina EA, Demin AM, Shevelev $\mathrm{OB}$, et al. Hemozoin "knobs" in Opisthorchis felineus infected liver. Parasites Vectors. (2015) 8:459. doi: 10.1186/s13071-015-1061-5

16. Lvova M, Zhukova M, Kiseleva E, Mayboroda O, Hensbergen P, Kizilova E, et al. Hemozoin is a product of heme detoxification in the gut of the most medically important species of the family Opisthorchiidae. Int J Parasitol. (2016) 46:147-56. doi: 10.1016/j.ijpara.2015.12.003

17. Olliaro P, Lombardi L, Frigerio S, Basilico N, Taramelli D, Monti D. Phagocytosis of hemozoin (native and synthetic malaria pigment), and Plasmodium falciparum intraerythrocyte-stage parasites by human and mouse phagocytes. Ultrastruct Pathol. (2000) 24:9-13. doi: 10.1080/019131200281264

18. Skorokhod OA, Alessio M, Mordmüller B, Arese P, Schwarzer E. Hemozoin (malarial pigment) inhibits differentiation and maturation of human monocyte-derived dendritic cells: a peroxisome proliferatoractivated receptor-gamma-mediated effect. J Immunol. (2004) 173:4066-74. doi: 10.4049/jimmunol.173.6.4066
19. Bujila I, Schwarzer E, Skorokhod O, Weidner JM, Troye-Blomberg M, Östlund Farrants AK. Malaria-derived hemozoin exerts early modulatory effects on the phenotype and maturation of human dendritic cells. Cell Microbiol. (2016) 18:413-23. doi: 10.1111/cmi.12521

20. Keller CC, Yamo O, Ouma C, Ong'echa JM, Ounah D, Hittner JB, et al. Acquisition of hemozoin by monocytes down-regulates interleukin-12 p40 (IL-12p40) transcripts and circulating IL-12p70 through an IL-10-dependent mechanism: in vivo and in vitro findings in severe malarial anemia. Infect Immun. (2006) 74:5249-60. doi: 10.1128/IAI.00843-06

21. Wills-Karp M, Santeliz J, Karp CL. The germless theory of allergic disease: revisiting the hygiene hypothesis. Nat Rev Immunol. (2001) 1:69-75. doi: 10.1038/35095579

22. Yazdanbakhsh M, Kremsner PG, van Ree R. Allergy, parasites, and the hygiene hypothesis. Science. (2002) 296:490-4. doi: 10.1126/science.296.5567.490

23. Rook GA. Review series on helminths, immune modulation and the hygiene hypothesis: the broader implications of the hygiene hypothesis. Immunology. (2009) 126:3-11. doi: 10.1111/j.1365-2567.2008.03007.x

24. Wu Z, Wang L, Tang Y, Sun X. Parasite-derived proteins for the treatment of allergies and autoimmune diseases. Front Microbiol. (2017) 8:2164. doi: $10.3389 /$ fmicb.2017.02164

25. Hamid F, Versteeg SA, Wiria AE, Wammes LJ, Wahyuni S, Supali T, et al. Molecular diagnostics and lack of clinical allergy in helminthendemic areas in Indonesia. J Allergy Clin Immunol. (2017) 140:1196-9.e6. doi: 10.1016/j.jaci.2017.04.040

26. Pacífico LG, Marinho FA, Fonseca CT, Barsante MM, Pinho V, Sales-Junior $\mathrm{PA}$, et al. Schistosoma mansoni antigens modulate experimental allergic asthma in a murine model: a major role for CD4+ CD25+ Foxp3+ $\mathrm{T}$ cells independent of interleukin-10. Infect Immun. (2009) 77:98-107. doi: 10.1128/IAI.00783-07

27. Dittrich AM, Erbacher A, Specht S, Diesner F, Krokowski M, Avagyan A, et al. Helminth infection with Litomosoides sigmodontis induces regulatory $\mathrm{T}$ cells and inhibits allergic sensitization, airway inflammation, and hyperreactivity in a murine asthma model. J Immunol. (2008) 180:1792-9. doi: 10.4049/jimmunol.180.3.1792

28. Ogorodova LM, Fedorova OS, Sripa B, Mordvinov VA, Katokhin AV, Keiser J, et al. Opisthorchiasis: an overlooked danger. PLoS Negl Trop Dis. (2015) 9:e0003563. doi: 10.1371/journal.pntd.0003563

29. Fedorova OS, Kovshirina YV, Kovshirina AE, Fedotova MM, Deev IA, Petrovskiy FI, et al. Opisthorchis felineus infection and cholangiocarcinoma in the Russian Federation: a review of medical statistics. Parasitol Int. (2017) 66:365-71. doi: 10.1016/j.parint.2016.07.010

30. Ogorodova LM, Freidin MB, Sazonov AE, Fedorova OS, Gerbek IE, Cherevko NA, et al. A pilot screening of prevalence of atopic states and opisthorchosis and their relationship in people of Tomsk Oblast. Parasitol Res. (2007) 101:1165-8. doi: 10.1007/s00436-007-0588-6

31. Fedorova OS, Janse JJ, Ogorodova LM, Fedotova MM, Achterberg RA, Verweij JJ, et al. Opisthorchis felineus negatively associates with skin test reactivity in Russia-EuroPrevall-International Cooperation study. Allergy. (2017) 72:1096104. doi: 10.1111/all.13120

32. Saltykova IV, Ogorodova LM, Bragina EY, Puzyrev VP, Freidin MB. Opisthorchis felineus liver fluke invasion is an environmental factor modifying genetic risk of atopic bronchial asthma. Acta Trop. (2014) 139:53-6. doi: 10.1016/j.actatropica.2014.07.004

33. Daniłowicz-Luebert E, Steinfelder S, Kühl AA, Drozdenko G, Lucius R, Worm $\mathrm{M}$, et al. A nematode immunomodulator suppresses grass pollen-specific allergic responses by controlling excessive Th2 inflammation. Int J Parasitol. (2013) 43:201-10. doi: 10.1016/j.ijpara.2012.10.014

34. Kitagaki K, Businga TR, Racila D, Elliott DE, Weinstock J V, Kline JN. Intestinal helminths protect in a murine model of asthma. J Immunol. (2006) 177:1628-35. doi: 10.4049/jimmunol.177.3.1628

35. Qiu S, Fan X, Yang Y, Dong P, Zhou W, Xu Y, et al. Schistosoma japonicum infection downregulates house dust miteinduced allergic airway inflammation in mice. Fan G-C, editor. PLoS ONE. (2017) 12:e0179565. doi: 10.1371/journal.pone.017 9565

36. Bligh EG, Dyer WJ. A rapid method of total lipid extraction and purification. Can J Biochem Physiol. (1959) 37:911-7. doi: 10.1139/y59-099 
37. Chomczynski P, Wilfinger W, Kennedy A, Rymaszewski M, Mackey K. RNAzol ${ }^{\circledR}$ RT: a new single-step method for isolation of RNA. Nat Methods. (2010) 7:4-5. doi: 10.1038/nmeth.f.315

38. Livak KJ, Schmittgen TD. Analysis of relative gene expression data using realtime quantitative PCR and the 2(-delta delta C(T)) Method. Methods. (2001) 25:402-8. doi: 10.1006/meth.2001.1262

39. Yuryeva K, Saltykova I, Ogorodova L, Kirillova N, Kulikov E, Korotkaya E, et al. Expression of adenosine receptors in monocytes from patients with bronchial asthma. Biochem Biophys Res Commun. (2015) 464:1314-20. doi: 10.1016/j.bbrc.2015.07.141

40. Blüml S, Kirchberger S, Bochkov VN, Krönke G, Stuhlmeier K, Majdic $\mathrm{O}$, et al. Oxidized phospholipids negatively regulate dendritic cell maturation induced by TLRs and CD40. J Immunol. (2005) 175:501-8. doi: 10.4049/jimmunol.175.1.501

41. Bateman ED, Hurd SS, Barnes PJ, Bousquet J, Drazen JM, FitzGerald JM, et al. Global strategy for asthma management and prevention: GINA executive summary. Eur Respir J. (2008) 31:143-78. doi: 10.1183/09031936.00138707

42. Coban C, Yagi M, Ohata K, Igari Y, Tsukui T, Horii T, et al. The malarial metabolite hemozoin and its potential use as a vaccine adjuvant. Allergol Int. (2010) 59:115-24. doi: 10.2332/allergolint.10-RAI-0194

43. Ong'echa JM, Remo AM, Kristoff J, Hittner JB, Were T, Ouma C, et al. Increased circulating interleukin (IL)-23 in children with malarial anemia: in vivo and in vitro relationship with co-regulatory cytokines IL-12 and IL-10. Clin Immunol. (2008) 126:211-21. doi: 10.1016/j.clim.2007.08.007

44. Barrera V, Skorokhod OA, Baci D, Gremo G, Arese P, Schwarzer E. Host fibrinogen stably bound to hemozoin rapidly activates monocytes via TLR4 and CD11b/CD18-integrin: a new paradigm of hemozoin action. Blood. (2011) 117:5674-82. doi: 10.1182/blood-2010-10-312413
45. Li M, Wang ZN, Yang LF, Yan Y, Cai LM, Li YT, et al. TLR4 antagonist suppresses airway remodeling in asthma by inhibiting the T-helper 2 response. Exp Ther Med. (2017) 14:2911-6. doi: 10.3892/etm.2017.4898

46. Mobley JL, Chin JE, Richards IM. Cytokine networks in allergic lung inflammation: an opportunity for drug intervention. Expert Opin Investig Drugs. (1997) 6:1-6. doi: 10.1517/13543784.6.1.1

47. Couper KN, Blount DG, Riley EM. IL-10: the master regulator of immunity to infection. J Immunol. (2008) 180:5771-7. doi: 10.4049/jimmunol.180.9.5771

48. Kremer E, Ogorodova LM, Kirillova NA, Khvorilova K V, Perevozchikova $\mathrm{T} \mathrm{V}$, Fait EA. Immunophenotypic characteristic of dendritic cells in bronchial asthma in conditions of extract Opisthorchis felineus in vitro. Vestn Ross Akad Med Nauk. (2013) 5:66-70. doi: 10.15690/vramn.v68i5 .665

49. Chico ME, Vaca MG, Rodriguez A, Cooper PJ. Soil-transmitted helminth parasites and allergy: observations from Ecuador. Parasite Immunol. (2018) 41:e12590. doi: 10.1111/pim.12590

Conflict of Interest: The authors declare that the research was conducted in the absence of any commercial or financial relationships that could be construed as a potential conflict of interest.

Copyright (c) 2019 Saltykova, Ittiprasert, Nevskaya, Dorofeeva, Kirillova, Kulikov, Ivanov, Mann, Pershina and Brindley. This is an open-access article distributed under the terms of the Creative Commons Attribution License (CC BY). The use, distribution or reproduction in other forums is permitted, provided the original author(s) and the copyright owner(s) are credited and that the original publication in this journal is cited, in accordance with accepted academic practice. No use, distribution or reproduction is permitted which does not comply with these terms. 